\title{
Perceived stigma among non-professional caregivers of people with severe mental illness, Bahir Dar, northwest Ethiopia
}

Temesgen Ergetie ${ }^{1 *}$, Zegeye Yohanes$^{2}$, Biksegn Asrat $^{3}$, Wubit Demeke $^{2}$, Andargie Abate $^{4}$ and Minale Tareke ${ }^{1}$

\begin{abstract}
Background: The stigmatization of mental illness is currently considered to be one of the most important issues facing caregivers of severely mentally ill individuals. There is a dearth of information about the prevalence and associated factors of perceived stigma among caregivers of people with severe mental illness in the study area.

Objective: To assess the prevalence and associated factors of perceived stigma among non-professional caregivers of people with severe mental illness, Bahir Dar, northwest Ethiopia.

Method: Institutional based cross-sectional study was conducted from May to June, 2016 at Felege Hiwot Referral Hospital among 495 caregivers of people with the severe mental illness. Pre-tested structured family interview schedule questionnaire was used. Binary logistic regression was applied to identify factors associated with perceived stigma and interpreted using odds ratio with 95\% confidence interval. Statistical significance was considered at $p$ value $<0.05$.

Result: The overall prevalence of perceived stigma was found to be $89.3 \%$. Being female, rural residency, lack of social support, long duration of relationship with the patient and currently not married were found significantly associated with the perceived stigma of caregivers.
\end{abstract}

Conclusion: Prevalence of perceived stigma is very high in the current study. Thus, stigma reduction program and expanding of strong social support should better be implemented by different stakeholders for caregivers of people with severe mental illness.

Keywords: Caregivers, Perceived stigma, Severe mental illness

\section{Introduction}

The burden of mental health problems is increasing globally [1]. Mental illness accounted for $13 \%$ of world's disease burden and this figure will be increased to $15 \%$ by the year 2020 [2, 3]. Studies showed that approximately 450 million persons affected by mental illness and their devastating effects at personal and national levels are quite significant $[1,2,4]$. Due to different reasons, in low- and middle-income countries, about third quarter of people who need mental health service do not get any kind of intervention [5]. Stigma is one of the barriers that

\footnotetext{
*Correspondence: Tomtemesgen@gmail.com

${ }^{1}$ Department of Psychiatry, College of Medicine and Health Sciences,

Bahir Dar University, Po box 79, Bahir Dar, Ethiopia

Full list of author information is available at the end of the article
}

can prevent patients with mental illnesses from getting appropriate treatment or care [6].

Stigma is a social process, practiced or expected and characterized by separation, rejection, and blame or discredit about an individual or groups [7]. Stigma occurs at three levels, namely, organizational, public and personal level. Organizational stigma refers to the stigma that exists at system level which is defined as the rules, policies, and procedures of private and governmental entities in positions of power that restrict the rights and chances of people with disabling conditions [8]. Public stigma occurs at the group level and can be defined as the trends of massive social groups endorsing stereotype behavior and acting against a stigmatized group [9]. Personal level stigma is the stigma existing at the individual level. Perceived stigma existing at the 
personal level which is respondent's beliefs in which those people with mental illness are generally stigmatized [10].

Facing stigmatization of mentally ill individual is one of the most important issues in mental health field until now [11]. It involves an isolation of person labeled as different from "us" who are believed to possess negative traits, resulting in negative feelings, discrimination, and status loss for the marginalized persons [12].

Feeling of stigmatization was not the only problem of people with severe mental illness, but also their family members who help care for them report feeling stigmatized as a result of their relationship with the loved one with mental illness [13-16]. Practically, $43-92 \%$ of the care providers of people with mental illness reported the feeling of being stigmatized [17]. In the United States, a study revealed that $43 \%$ of caregivers of people with mental illness perceived that they were stigmatized by others because of having a mentally ill individual within their relatives [15]. In Morocco, caregivers of schizophrenia patients reported high level of perceived stigma and faced serious impacts on their family members [18]. A community-based study conducted in Ethiopia showed that perceived stigma was $75 \%$ among caregivers of people with severe mental illness (SMI) [19]. Perceived stigma has affected caregivers of people with SMI in several ways including emotional, relationship, financial, health, and time stressors. They also described the feeling of being separated, ignored, blamed and criticized by peers, neighbors, coworkers and even mental health professionals [20]. Caregivers of people with mental illness are exposed to shame, low self-worth, and social isolation as a result of perceived stigma. Caregivers' expectation of devaluation and discrimination from others leads them to adopt harmful coping mechanisms such as secrecy or withdrawal. As a result, caregivers hide patients, and patients may not get proper treatment or will be noncompliance [13].

A study revealed that perceived stigma of caregivers is associated with higher education, living with the patient in an urbanized area, being female, and a patient who had early age onset of illness, multiple admission and longer duration of the illness [14].

Even though studies around the globe demonstrated the high magnitude of perceived stigma, in Ethiopia, there are few previous studies that reported on perceived stigma specifically among non-professional caregivers of people with SMI.

Therefore, this study was proposed to determine the magnitude of perceived stigma and predictive factors among non-professional caregivers of people with SMI in the study area.

\section{Methods}

\section{Study design and period}

The facility-based cross-sectional study was conducted from May to June 2016 at Felege-Hiwot Referral Hospital (FHRH). The Hospital is found in the capital city of Amhara Regional state which is located $553 \mathrm{~km}$ far from the capital city of Ethiopia, Addis Ababa. It was established in 1963 as district hospital and changed into referral hospital in 2002. Psychiatry unit was established in 1990 and currently, there are five psychiatry outpatient units which provide services for about 70-90 patients per day.

\section{Sample size determination and sampling procedure Sample size and Sampling procedures}

The sample size was determined using single-population proportion formula $[n=((z \alpha / 2) 2 p(1-p)) / d 2]$ with the following assumptions: $95 \%$ confidence interval (CI) $(Z \alpha / 2=1.96)$ and the proportion $(p)$ of perceived stigma of caregivers to be $75 \%$ from previous study at Buta Jira [19], marginal error 4\%. By adding $10 \%$ non-response rate, a total of 495 study populations were involved.

The study participants were selected using systematic random sampling technique. The numbers of patients with SMI who had monthly regular follow-up estimated were 1482; of these, 526 people with schizophrenia, major depressive disorder (MDD) (600) and bipolar disorders (356). The total sample size was allocated proportionally to each SMI patient caregivers. Sampling fraction was 3 (i.e. $1482 / 495 \approx 3$ ) for all samples. Lottery method was used to get the first participant who arrived at outpatient settings for each type of severely mentally ill patients' caregivers. Then after, ever 3rd caregivers were interviewed according to their arrival in outpatient settings for each type of caregivers independently. A caregiver who provides more care was interviewed when the patient had more than one caregiver.

\section{Operational definitions Caregiver}

Someone who provided more than 6 months of care and regularly responsible for taking care of patients more than other immediate or non-immediate family relative rather than by a health professional.

\section{Immediate family relative}

Father/mother, son/daughter and brother/sister. 


\section{Non-immediate family relative}

Other relatives and friends.

\section{Severe mental illness}

Mental illness that includes schizophrenia, major depressive and bipolar disorders.

\section{Data-collection instruments and procedures}

Data were collected using standardized Family Interview Schedule (FIS) questionnaire, which was developed as part of a world health organization study on the course and outcome of schizophrenia [21]. FIS questionnaire was 14-item questions regarding stigma that might affect families. Each stigma item was rated on a four-point scale, not at all (0), sometimes (1), often (2) and a lot (3) with respect to stigma. To assess the distribution of stigma responses between groups, a stigma sum score was computed by summarizing all positive responses $(\geq 1)$ for each of the 14 items. The presence of just one positive answer on the stigma questionnaire was enough to represent a form of perceived stigma [19].

Social support was measured using the Oslo-3 Social Support Scale (OSS-3) with three questions. We used the sum score scale ranging from 3 to 14 , which has three broad categories: "poor support" 3-8, "moderate support" 9-11 and "strong support" 12-14 [22].

A semi-structured questionnaire was used to collect socio-demographic, relationship and clinical factors. Data were collected using pre-tested structured questionnaires using face to face interview. Five data collectors (BSc nurses) and one MSc in mental health supervisor were recruited to conduct face to face interview of the caregivers for a month duration.

\section{Data quality management}

Data quality control issue is ensured by conducting pretest among 25 caregivers in the study area 1 week before the actual data-collection periods. One-day training was given for data collectors and supervisors on how to use the questionnaires, how to approach the participants of the study and about the purpose of the study. In addition to this, English questionnaires were translated to local language respondents' Amharic language. Supervisor and principal investigator were closely followed the whole period of data-collection process. Supervision was held regularly during the data-collection period. Collected data were checked on a daily basis for its completeness.

\section{Data processing and analysis}

Data were checked, coded, cleaned and entered into Epi-Info version 7 and exported to SPSS version 20 for analysis. Frequency, percentage, mean, standard deviation, tables, and charts were used to report the results of the data. Bivariate logistic regression analysis used to examine the association between dependent and independent variables. All variables with $p<0.2$ in bivariate analysis were fitted into the multivariate logistic regression model to identify factors associated with perceived stigma. The association was interpreted using odds ratio and $95 \%$ confidence interval. $p<0.05$ was considered statistically significant in this study.

\section{Ethical consideration}

Ethical clearance obtained from University of Gondar ethical review board committee before data-collection period. The official letter was obtained and given for Amhara regional health bureau and Felege-Hiwot Referral Hospital. The study participants were informed about the purpose of the study. Written informed consent was obtained from participants during data-collection period, and they were informed that participation was on the voluntary basis and had full right to withdraw at any time during the interview process. They were also informed that refusal to participate had no negative consequences on the patients' care, and participation had no financial benefit. Confidentiality was maintained throughout the study.

\section{Results}

\section{Socio-demographic characteristics}

Out of 495 recruited caregivers, 478 participated in the study yielding a response rate of $96.56 \%$. The mean age of caregivers was $37.08( \pm 13.4 \mathrm{SD})$ years. Nearly half of caregivers were females 244 (51\%) and rural residents 262 (54.8\%). Majority of respondents were Amhara by ethnicity 469 (98.1\%), Orthodox religion follower 384 (80.3\%) and currently not married 374 (78.2\%) (Table 1$)$.

\section{Psychosocial factors}

Nearly half of the caregivers had poor social support 260 (54.4\%), others had moderate social supports 136 (28.5\%), and strong social supports 82 (17.1\%).

\section{Relationship factors}

Caregivers who have the duration of relationship with the patient for about 20-39 years were 238 (49.8\%) and not live together with the patient 279 (58.4\%) (Table 2).

\section{Clinical factors}

Almost half of patient's illness onset was below the ages of 20 years $262(54.8 \%)$ and $307(64.2 \%)$ had history of admission (Table 3). 
Table 1 Socio-demographic characteristics of caregivers at Felege-Hiwot Referral Hospital, Bahir Dar, northwest Ethiopia, July, $2016(n=478)$

\begin{tabular}{|c|c|c|c|}
\hline Variables & Categories & Frequency & Percent \\
\hline \multirow[t]{5}{*}{ Age } & $18-24$ & 89 & 18.6 \\
\hline & $25-34$ & 138 & 28.9 \\
\hline & $35-44$ & 108 & 22.6 \\
\hline & $44-54$ & 81 & 16.9 \\
\hline & $\geq 55$ & 62 & 13 \\
\hline \multirow[t]{2}{*}{ Sex } & Male & 234 & 49 \\
\hline & Female & 244 & 51 \\
\hline \multirow[t]{2}{*}{ Residence } & Urban & 216 & 45.2 \\
\hline & Rural & 262 & 54.8 \\
\hline \multirow[t]{2}{*}{ Ethnicity } & Amhara & 469 & 98.1 \\
\hline & Others $^{\mathrm{a}}$ & 9 & 1.9 \\
\hline \multirow[t]{3}{*}{ Religion } & Orthodox & 384 & 80.3 \\
\hline & Muslim & 88 & 18.4 \\
\hline & Others $^{b}$ & 6 & 1.3 \\
\hline \multirow[t]{2}{*}{ Marital status } & Currently not married & 374 & 78.2 \\
\hline & Currently married & 104 & 21.8 \\
\hline \multirow[t]{4}{*}{ Educational status } & Unable to read and write & 121 & 25.3 \\
\hline & Primary & 115 & 24.1 \\
\hline & Secondary & 90 & 18.8 \\
\hline & Diploma and above & 152 & 31.8 \\
\hline \multirow[t]{6}{*}{ Job } & Government employee & 73 & 15.3 \\
\hline & Private employee & 72 & 15.1 \\
\hline & Merchant & 65 & 13.6 \\
\hline & Farmer & 143 & 29.9 \\
\hline & House wife & 71 & 14.9 \\
\hline & Student & 54 & 11.3 \\
\hline
\end{tabular}

Others $^{\mathrm{a}}=$ Tigrie, Oromo and Guragie; Others ${ }^{\mathrm{b}}=$ Protestant and Catholic

Table 2 Relationship factors of caregivers of people with SMI at Felege-Hiwot Referral Hospital, Bahir Dar, northwest Ethiopia, July, $2016(n=478)$

\begin{tabular}{llcc}
\hline Variables & Categories & Frequency & Percent \\
\hline Type of relationship & Mother & 64 & 13.4 \\
& Father & 113 & 23.6 \\
& Spouse & 98 & 20.5 \\
& Child & 75 & 15.7 \\
& Brother/sister & 83 & 17.4 \\
& Other relatives/friends & 45 & 9.4 \\
Duration of relation- & 0-19 & 181 & 37.9 \\
ship with the & 20-39 & 238 & 49.8 \\
patient (years) & $40-59$ & 59 & 12.3 \\
Do you live together & Yes & 199 & 41.6 \\
with patients & No & 279 & 58.4 \\
\hline
\end{tabular}

Table 3 Clinical factors of caregivers of people with SMI at Felege-Hiwot Referral Hospital, Bahir Dar, northwest Ethiopia, July, $2016(n=478)$

\begin{tabular}{llll}
\hline Variables & Categories & Frequency & Percent \\
\hline Types of diagnosis & Schizophrenia & 175 & 36.6 \\
& Bipolar disorders & 115 & 24.1 \\
& MDD & 188 & 39.3 \\
Age of illness onset (years) & $\leq 20$ & 262 & 54.8 \\
& $21-40$ & 135 & 28.2 \\
& $\geq 40$ & 81 & 16.9 \\
Duration patient's Illness & $\leq 1$ & 111 & 23.2 \\
(years) & $>1$ & 367 & 76.8 \\
Duration of treatment of & $\leq 1$ & 205 & 42.9 \\
patients (years) & $2-5$ & 178 & 37.2 \\
& $6-10$ & 75 & 15.7 \\
& $\geq 11$ & 20 & 4.2 \\
Admission & No & 171 & 35.8 \\
& Yes & 307 & 64.2 \\
\hline
\end{tabular}

\section{Prevalence of perceived stigma}

The prevalence of perceived stigma in our study was 89.3\% (95\%, CI 84.6, 91.9). The mean and standard deviation of FIS scale was 7.6 and 8.1 respectively and its minimum and maximum value ranges from 0 to 34 . Regarding the proportion of perceived stigma toward each item, three quarters $(75.2 \%)$ of the caregivers agreed with the item "Felt grief or depression because of it", followed by "Helping other people to understand what it is like to have a family member with psychiatric problem' '(43.9\%). The least frequently endorsed item was 'felt that somehow it might be your fault' (14.6\%) (Table 4).

\section{Associated factors with perceived stigma}

In the bivariate logistic regression analysis, sex, residence, social support, age of onset of illness, patient's duration of treatment, marital status, care giver's educational level, patient's numbers of hospital admission and duration of relationship with the patient were significantly associated with previewed stigma at $p$ value $<0.2$ level and entered for further analysis into multivariate logistic regression to control confounding factors. On the other hand, ethnicity, religion, types of diagnosis, duration of illness, the age of respondents, job, types of the relationship of caregivers with the patient and living together or not living together were not statistically significant. In the logistic regression, 
Table 4 Proportion of perceived stigma response of caregivers to each item at Felege-Hiwot Referral Hospital, Bahir Dar, northwest Ethiopia, July, $2016(n=478)$

\begin{tabular}{|c|c|c|c|c|c|c|}
\hline \multirow[t]{2}{*}{ S. no } & \multirow[t]{2}{*}{ Items } & \multirow{2}{*}{$\begin{array}{l}\text { Negative responses } \\
\text { Not at all total (\%) }\end{array}$} & \multicolumn{4}{|c|}{ Any positive response } \\
\hline & & & Some times & Often & A lot & Total (\%) \\
\hline 1 & Worried about being treated differently & $365(76.4 \%)$ & 58 & 14 & 41 & $113(23.6 \%)$ \\
\hline 2 & Worried people would know about it & $352(73.7 \%)$ & 46 & 27 & 53 & $126(26.3 \%)$ \\
\hline 3 & Felt the need to hide this fact & $356(74.4 \%)$ & 52 & 21 & 49 & $122(25.6 \%)$ \\
\hline 4 & $\begin{array}{l}\text { Helping other people to understand what it is like to have a family member } \\
\text { with psychiatric problem }\end{array}$ & $268(56.1 \%)$ & 134 & 33 & 43 & $210(43.9 \%)$ \\
\hline 5 & Making an effort to keep this fact a secret & $349(73 \%)$ & 57 & 23 & 49 & $129(27 \%)$ \\
\hline 6 & Worried about being avoided & $381(80 \%)$ & 46 & 24 & 27 & 97 (20\%) \\
\hline 7 & Explaining to others that (name) isn't like their picture of "crazy" people & $341(71.3 \%)$ & 85 & 25 & 27 & $137(28.7 \%)$ \\
\hline 8 & Worried that people would blame you for his or her problems & $401(83.9 \%)$ & 44 & 18 & 15 & $77(16.1 \%)$ \\
\hline 9 & $\begin{array}{l}\text { Worried that a person looking to marry would be reluctant to marry into } \\
\text { your family }\end{array}$ & $352(73.6 \%)$ & 54 & 20 & 52 & $126(26.4 \%)$ \\
\hline 10 & Worried about taking him or her out & $359(75.1 \%)$ & 48 & 17 & 54 & $126(24.9 \%)$ \\
\hline 11 & Felt ashamed or embarrassed about it & $335(70.1 \%)$ & 125 & 17 & 1 & $143(29.9)$ \\
\hline 12 & $\begin{array}{l}\text { Sought out people who also have a family member who has had psychiatric } \\
\text { problem }\end{array}$ & $301(63 \%)$ & 79 & 20 & 78 & $177(37 \%)$ \\
\hline 13 & Felt grief or depression because of it & $119(24.9 \%)$ & 140 & 61 & 158 & $359(75.1 \%)$ \\
\hline 14 & Felt that somehow it might be your fault & $408(85.4 \%)$ & 50 & 12 & 8 & $70(14.6 \%)$ \\
\hline
\end{tabular}

after controlling confounding factors, sex, residency, social support, marital statuses, and numbers of admission and duration of relationship with the patient were found statistically significant.

Female caregivers were three times more likely to have perceived stigma compared to male caregivers $(\mathrm{AOR}=3.02,95 \% \mathrm{CI} 1.30,7.11)$, not currently married were three times more likely to have perceived stigma compared to currently married caregivers $(\mathrm{AOR}=3.20$, $95 \%$ CI $1.48,6.91$ ) and caregivers who lived in rural were three times more likely to have perceived stigma compared to who lived in urban areas $(\mathrm{AOR}=2.80,95 \% \mathrm{CI}$ $1.20,6.54)$. Caregivers who had poor social support were five times more likely to have perceived stigma compared to caregivers who have strong social support $(\mathrm{AOR}=5.06,95 \% \mathrm{CI} 1.96,13.13)$.

Caregivers who gave care for patients for 20-39year duration were five times more likely to have perceived stigma compared to those who gave care for 6 months -19 years of duration $(\mathrm{AOR}=4.92,95 \% \mathrm{CI} 1.30$, 18.67). In addition to this, caregivers who cared for the patient who had the history of admission were $77 \%$ less likely to have perceived stigma compared those who gave no history of admission $(\mathrm{AOR}=0.23,95 \% \mathrm{CI}=0.10,0.51$ ) (Table 5).

\section{Discussion}

The increment in the prevalence of perceived stigma globally needs a better understanding of the local burden and most common influencing factors. In the current study, the overall prevalence of perceived stigma among caregivers of people with SMI was found to be $89.3 \%$ which was in line with the study done in Morocco which was $86.7 \%$ [18].

However, the prevalence in this study was higher than the prevalence reported in the United States (43\%), Belgium $(86 \%)$ and Butajira, Ethiopia $(75 \%)$ [15, 19, 23]. The difference might be due to variation in sample size, instruments they used, cultural, socio-demographic characteristics of participants and study population. In addition to this, perceived stigma in our study might be due to a misperception about mental illness and most of the time people believed that mental illness is happened as a result of supernatural punishment. Furthermore, the sample size in Butajira was 178 and conducted at the community level, however, the current study was done at health institution among 478 caregivers of people with SMI. There was also an educational status difference.

In this study, perceived stigma among female caregivers was higher than male caregivers, which was in line with the previous studies done in China and American [14, 24]. This might be due to the reason in which the role of caring and social burden for the female is more burdensome increasing their vulnerability to perceived stigma. 
Table 5 Factors associated with perceived stigma among caregivers of people with SMI attending at Felege-Hiwot Referral Hospital, Bahir Dar, northwest Ethiopia, July, $2016(n=478)$

\begin{tabular}{|c|c|c|c|c|c|}
\hline \multirow[t]{2}{*}{ Explanatory variables } & \multirow[t]{2}{*}{ Category } & \multicolumn{2}{|c|}{ Perceived stigma } & \multirow[t]{2}{*}{$\operatorname{COR}(95 \% \mathrm{Cl})$} & \multirow[t]{2}{*}{ AOR $(95 \% \mathrm{Cl})$} \\
\hline & & Yes & No & & \\
\hline \multirow[t]{2}{*}{ Sex } & Male & 199 & 35 & 1.0 & 1.0 \\
\hline & Female & 228 & 16 & $2.51(1.35,4.67)$ & $3.03(1.29,7.11)^{\mathrm{a}}$ \\
\hline \multirow[t]{2}{*}{ Residency } & Urban & 187 & 29 & 1.0 & 1.0 \\
\hline & Rural & 240 & 22 & $1.70(0.94,3.304)$ & $2.80(1.20,6.54)^{\mathrm{a}}$ \\
\hline \multirow[t]{3}{*}{ Social support } & Poor & 244 & 16 & $5.59(2.77,11.30)$ & $5.06(1.96,13.13)^{\mathrm{a}}$ \\
\hline & Moderate & 123 & 13 & $3.47(1.64,7.36)$ & $2.43(0.91,6.45)$ \\
\hline & Strong & 60 & 22 & 1.0 & 1.0 \\
\hline \multirow[t]{3}{*}{ Age onset of illness (years) } & $\leq 20$ & 254 & 8 & 1.0 & 1.0 \\
\hline & $21-39$ & 100 & 35 & $0.09(0.04,0.20)$ & $0.47(0.75,8.12)$ \\
\hline & $\geq 40$ & 73 & 8 & $0.29(0.10,0.79)$ & $0.40(0.14,1.13)$ \\
\hline \multirow[t]{4}{*}{ Duration of treatment (years) } & $<1$ & 191 & 14 & 1.0 & 1.0 \\
\hline & $2-5$ & 159 & 19 & $0.61(0.30,1.26)$ & $0.22(0.64,16.22)$ \\
\hline & $6-10$ & 64 & 11 & $0.43(0.18,0.99)$ & $0.14(0.62,15.85)$ \\
\hline & $\geq 11$ & 13 & 7 & $0.14(0.05,0.40)$ & $0.12(0.39,11.64)$ \\
\hline \multirow[t]{2}{*}{ Marital status } & Currently not married & 350 & 24 & $5.11(2.80,9.34)$ & $3.20(1.48,6.91)^{\mathrm{a}}$ \\
\hline & Currently married & 77 & 27 & 1.0 & 1.0 \\
\hline \multirow[t]{4}{*}{ Educational level } & Unable to read and write & 102 & 19 & $0.46(0.21,0.99)$ & $1.00(0.35,2.86)$ \\
\hline & Primary & 106 & 9 & $1.01(.41,0.2 .48)$ & $1.45(0.49,4.26)$ \\
\hline & Secondary & 79 & 11 & $0.62(0.26,1.46)$ & $0.74(0.26,2.06)$ \\
\hline & Diploma and above & 140 & 12 & 1.0 & 1.0 \\
\hline \multirow[t]{2}{*}{ History of admission } & No & 146 & 25 & 1.0 & 1.0 \\
\hline & Yes & 281 & 26 & $1.85(1.03,3.32)$ & $0.23(0.10,0.51)^{\mathrm{a}}$ \\
\hline \multirow[t]{3}{*}{ Duration of care for the patient } & 6 moths-19 years & 149 & 32 & 1.0 & 1.0 \\
\hline & 20-39 years & 227 & 11 & $4.43(2.17,9.10)$ & $4.92(1.30,18.67)^{\mathrm{a}}$ \\
\hline & $\geq 40$ years & 51 & 8 & $1.37(0.060,3.16)$ & $3.80(1.20,11.98)^{\mathrm{a}}$ \\
\hline
\end{tabular}

COR crude odds ratio, $A O R$ adjusted odds ratio

a Statistically significant at $p$ value $<0.05$

Caregivers who were currently not married and lived in the rural area were three times more likely to have perceived stigma compared to those who were currently married and lived in the urban area. This result has concurred with the findings documented in India and China $[25,26]$. This might be due to lack of intimate social support to share stressful feelings, having low self-esteem and poor coping mechanism which are common among not married people exposing them to have perceived stigma. This thought is supported by the current study stating that poor social support increased the level of perceived stigma. In addition, caregivers who lived in the rural area experienced the high level of perceived stigma. These could be due to rural residents' lack of awareness and cultural belief about the causes of mental illness such as spiritual possessions, the result of a sinful act or punishment from God [27].

Caregivers who had poor social support were five times more likely to have perceived stigma compared to those with strong social support. This result is in line with the data from a study conducted in China [26]. The possible reason could be the assumptions that caregivers who had a mentally ill person with family members might isolate themselves from the societies and cannot share different roles, responsibilities and their feelings.

Regarding duration of patient care, those who gave care for longer duration were more likely to have perceived stigma than those who gave care for a relatively shorter duration which is in line with the previous result in China [14]. Perception of stigma may be increased when the duration of caring increased. Because caring for people with severe mental illness causes a burden for caregivers in every aspect of life including economic, social, financial, physical and psychological consequences.

Admitted patient caregivers had a lower level of perceived stigma compared to caregivers who had no SMI family members with a history of admission. The current finding is inconsistent with the previous institution-based 
study was done in China [14]. The difference might be due to the difference in study design (follow-up study), measurement tool (Camberwell Family Interview) and study population (schizophrenia caregivers) in China. Moreover, the information might create awareness since they exchange information about mental illness with different health professionals and other peoples who cared people with several mental illnesses during their hospital stay.

\section{Limitation of the study}

Since the study was conducted only using quantitative design, it might not explore well the perception of caregivers' perceived stigma. In addition, a way of using an interpretation tool may exaggerate the presence of perceived stigma. Most comparison parts of discussions are not culturally matched.

\section{Conclusion}

This study finding showed a high prevalence of perceived stigma among caregivers of people with severe mental illness at Felege-Hiwot Referral Hospital, Bahir Dar. Being female, rural residency, poor social support, currently not being married and long duration of caring for patient were found to be significantly associated with the perceived stigma of caregivers of people with the severe mental illness. Therefore, it is very important to increase strong social support towards caregivers of people with mental illness by collaborating with different stakeholders and link them to support groups such as nongovernmental organizations and social workers, and to formulate certain interventions that focus on reduction of perceived stigma among caregivers.

\section{Authors' contributions}

TE conceived and designed the study. TE organized the data-collection process. TE, ZY, WD, BA, AA, and MT analyzed the data. TE and MT prepared the manuscript. All authors read and approved the final manuscript.

\section{Author details \\ ${ }^{1}$ Department of Psychiatry, College of Medicine and Health Sciences, Bahir Dar University, Po box 79, Bahir Dar, Ethiopia. ${ }^{2}$ Amanuel Specialized Mental Hospital, Addis Ababa, Ethiopia. ${ }^{3}$ Department of Psychiatry, College of Medi- cine and Health Sciences, Gondar University, Gondar, Ethiopia. ${ }^{4}$ College of Medicine and Health Sciences, Bahir Dar University, Po box 79, Bahir Dar, Ethiopia.}

\section{Acknowledgements}

The authors would like to thank the data collectors, supervisor, study participants and Felege-Hiwot Referral Hospital psychiatry clinic staffs for their genuine cooperation during the study period.

\section{Competing interests}

The authors declare that they have no competing interests.

\section{Consent for publication}

Not applicable.
Ethics approval and consent to participate

Ethical clearance obtained from University of Gondar ethical review board committee before data-collection period. The official letter was obtained and given for Amhara regional health bureau and Felege-Hiwot Referral Hospital. The study participants were informed about the purpose of the study. Written informed consent was obtained from participants during data-collection period and they were informed that participation was on the voluntary basis and had full right to withdraw at any time during the interview process. They were also informed that refusal to participate had no negative consequences on the patients' care, and participation had no financial benefit. Confidentiality was maintained throughout the study.

\section{Funding}

The research is funded by the University of Gondar.

\section{Publisher's Note}

Springer Nature remains neutral with regard to jurisdictional claims in published maps and institutional affiliations.

Received: 28 March 2018 Accepted: 26 September 2018

Published online: 08 October 2018

References

1. Organization $\mathbf{W H}$. The world health report 2001: mental health: new understanding, new hope. Geneva: World Health Organization; 2001.

2. Desjarlais R. World mental health: problems and priorities in low-income countries. Oxford: Oxford University Press; 1995.

3. Murray CJ, Lopez AD. Global burden of disease. Cambridge: Harvard University Press; 1996.

4. Rafiyah I. burden on family caregivers caring for patients with schizophrenia and its related factors. Nurs Media J Nurs. 2011;1(1):29-41.

5. Andrews L. Non-specialist health worker interventions for the care of mental, neurological, and substance-abuse disorders in low-and middleincome countries. Issues Ment Health Nurs. 2016;37(2):131-2.

6. Cooper AE, Corrigan PW, Watson AC. Mental illness stigma and care seeking. J Nerv Ment Dis. 2003;191(5):339-41.

7. Goffman E. Stigma: notes on the management of spoiled identity. New York: Simon and Schuster; 2009.

8. Corrigan PW, Kerr A, Knudsen L. The stigma of mental illness: explanatory models and methods for change. Appl Prev Psychol. 2005;11(3):179-90.

9. Werner P, Aviv A, Barak Y. Self-stigma, self-esteem and age in persons with schizophrenia. Int Psychogeriatr. 2008;20(1):174-87.

10. Griffiths KM, Christensen H, Jorm AF, Evans K, Groves C. Effect of web-based depression literacy and cognitive-behavioural therapy interventions on stigmatising attitudes to depression. Br J Psychiatry. 2004;185(4):342-9.

11. Crisp R. A qualitative study of the perceptions of individuals with disabilities concerning health and rehabilitation professionals. Disabil Soc. 2000;15(2):355-67.

12. Link BG, Yang LH, Phelan JC, Collins PY. Measuring mental illness stigma. Schizophr Bull. 2004;30(3):511-41.

13. Phelan JC, Bromet EJ, Link BG. Psychiatric illness and family stigma. Schizophr Bull. 1998;24(1):115-26.

14. Phillips MR, Pearson V, Li F, Xu M, Yang L. Stigma and expressed emotion: a study of people with schizophrenia and their family members in China. Br J Psychiatry. 2002;181(6):488-93.

15. Struening EL, Perlick DA, Link BG, Hellman F, Herman D, Sirey JA. Stigma as a barrier to recovery: the extent to which caregivers believe most people devalue consumers and their families. Psychiatric Serv. 2001;52(12):1633-8

16. Thara R, Srinivasan T. How stigmatising is schizophrenia in India? Int J Soc Psychiatry. 2000;46(2):135-41.

17. Van Brakel WH. Measuring health-related stigma-a literature review. Psychology Health Med. 2006;11(3):307-34. 
18. Kadri N, Manoudi F, Berrada S, Moussaoui D. Stigma impact on Moroccan families of patients with schizophrenia. Can J Psychiatry. 2004;49(9):625-9.

19. Shibre T, Negash A, Kullgren G, Kebede D, Alem A, Fekadu A, Fekadu D, Medhin $\mathrm{G}$, Jacobsson L. Perception of stigma among family members of individuals with schizophrenia and major affective disorders in rural Ethiopia. Soc Psychiatry Psychiatr Epidemiol. 2001;36(6):299-303.

20. Joanne Riebschleger PhDM, Maureen Mickus PhDM, Christine Liszewski MD, Eaton M. How are the experiences and needs of families of individuals with mental illness reflected in medical education guidelines? Acad Psychiatry. 2008;32(2):119.

21. Sartorius N, Janca A. Psychiatric assessment instruments developed by the World Health Organization. Soc Psychiatry Psychiatr Epidemiol. 1996;31(2):55-69.

22. Dalgard OS, Dowrick C, Lehtinen V, Vazquez-Barquero JL, Casey P, Wilkinson G, Ayuso-Mateos JL, Page H, Dunn G. Negative life events, social support and gender difference in depression. Soc Psychiatry Psychiatr Epidemiol. 2006;41(6):444-51.
23. Catthoor K, Schrijvers D, Hutsebaut J, Feenstra D, Persoons P, De Hert $M$, Peuskens J, Sabbe B. Associative stigma in family members of psychotic patients in Flanders: an exploratory study. World J Psychiatry. 2015;5(1):118.

24. Gonzalez JM, Perlick DA, Miklowitz DJ, Kaczynski R, Hernandez M, Rosenheck RA, Culver JL, Ostacher MJ, Bowden CL. Factors associated with stigma among caregivers of patients with bipolar disorder in the STEP-BD study. Psychiatric Serv. 2007;58(1):41-8.

25. Yannawar PB, Gajendragad JM, Gotewal S, Singh SB. Comparative study of perception of stigma among caregivers of persons with Bipolar affective disorder and Schizophrenia.

26. Yin Y, Zhang W, Hu Z, Jia F, Li Y, Xu H, Zhao S, Guo J, Tian D, Qu Z. Experiences of stigma and discrimination among caregivers of persons with schizophrenia in China: a field survey. PLoS ONE. 2014;9(9):e108527.

27. Tilahun D, Hanlon C, Fekadu A, Tekola B, Baheretibeb Y, Hoekstra RA. Stigma, explanatory models and unmet needs of caregivers of children with developmental disorders in a low-income African country: a crosssectional facility-based survey. BMC Health Serv Res. 2016;16(1):152.
Ready to submit your research? Choose BMC and benefit from:

- fast, convenient online submission

- thorough peer review by experienced researchers in your field

- rapid publication on acceptance

- support for research data, including large and complex data types

- gold Open Access which fosters wider collaboration and increased citations

- maximum visibility for your research: over 100M website views per year

At BMC, research is always in progress.

Learn more biomedcentral.com/submissions 